\title{
Stimulatory Effect of Cisplatin on Production of Lipid Peroxidation in Renal Tissues
}

\author{
Kumi SUGIHARA, Sachiko NAKANO, Michiko KODA, Katsumi TANAKA, \\ Nobuyuki FUKUISHI and Munekazu GEMBA* \\ Division of Pharmacology. Osaka University of Pharmaceutical Sciences, \\ Kawai. Matsubara. Osaka 580. Japan \\ Accepted November 15, 1986
}

\begin{abstract}
Cisplatin (cis-diamminedichloroplatinum 11), an anticancer chemotherapeutic agent with the dose-limiting side effect of nephrotoxicity, caused a statistically significant increase in lipid peroxidation. monitored by measuring the production of malondialdehyde, in rat kidney $72 \mathrm{hr}$ after injection. Treatment of rats beforehand with the antioxidant $\alpha$-tocopherol or $N$ - $N^{\prime}$-diphenyl-p-phenylenediamine (DPPD) effectively decreased such peroxidation. DPPD was a more effective inhibitor than $\alpha$-tocopherol, since it is known for its ability to scavenge free radicals more powerfully. The ability of renal cortical slices to accumulate $p$-aminohippurate (PAH) was examined as a biochemical parameter that would change in nephrotoxicity. The ability to accumulate PAH by the incubated slices decreased $72 \mathrm{hr}$ after administration of cisplatin. The pretreatment with DPPD prevented the decrease in PAH accumulation in the slices from rats treated with cisplatin. Structural changes of the renal proximal tubule caused by cisplatin. analyzed in a transmission electron microscope. were also prevented by the pretreatment with DPPD. The results suggest that cisplatin affects renal tissues in which free radicals generated by cisplatin may interact with membrane lipids to cause the production of lipid peroxidation. which affects both cellular structure and function.
\end{abstract}

cis-Diamminedichloroplatinum II (cisplatin) is a potent anticancer chemotherapeutic agent effective in the treatment of cancers of the testis, ovary, head and neck, and elsewhere. Unfortunately, it has doselimiting toxicity, the main effect being renal dysfunction caused by an unknown mechanism. McGinness et al. (1) found that Orgotein (having superoxide dismutase activity) ameliorates the nephrotoxicity of cisplatin. They concluded that the production of oxygen radicals is responsible for this nephrotoxicity. We have tried to evaluate further the importance of reactive free radicals in the nephrotoxicity of cisplatin (2). The increase in blood urea nitrogen and decrease in body weight caused by injection of cisplatin into rats are modified when an

* To whom all correspondence should be addressed. antioxidant, $\alpha$-tocopherol or $N$ - $N^{\prime}$-diphenyl$p$-phenylenediamine (DPPD), is given before the cisplatin injection. These results suggest that the toxic effect of cisplatin may be related to damage caused by free radicals. Abnormal levels of reactive oxygen radicals react with membrane lipids and cause an increase in lipid peroxidation. Uncontrolled lipid peroxidation can profoundly affect both membrane structure and function, and this may cause cell death $(3,4)$. The relationship of lipid peroxidation to the nephrotoxicity of cisplatin is not understood.

Here, experiments were designed to detect the production of lipid peroxidation in the kidney of rats treated with cisplatin. We also wished to see if an antioxidant such as DPPD or $\alpha$-tocopherol, which are nonspecific free radical scavengers, would affect the production of lipid peroxidation and biochemical 
and histological changes caused by cisplatin.

\section{Materials and Methods}

Animals: The animals used were male Sprague-Dawley rats. They were fed standard chow and given free access to water until they were killed. Their weight at the start of the experiment was $200 \mathrm{~g}$ on an average.

Treatment: The rats were injected i.p. with 5.0 or $7.5 \mathrm{mg}$ of cisplatin per kilogram of body weight. A dose of $0.5 \mathrm{~g} / \mathrm{kg}$ DPPD in corn oil, or else a dose of $1667 \mathrm{lU} / \mathrm{kg} \alpha$ tocopherol in $0.1 \%$ Tween 80 , was given i.p. $24 \mathrm{hr}$ before the injection of cisplatin in the experiment with antioxidant. Control rats received saline injections. At 24, 48, 72, 96 or $120 \mathrm{hr}$ after the injection of cisplatin, the animals were anesthetized with sodium pentobarbital (30 mg/kg, i.p.). Both kidneys were rapidly romoved and decapsulated in ice-cold saline $(0.9 \% \mathrm{NaCl})$. The kidneys were homogenized in a solution containing $0.15 \mathrm{M} \mathrm{KCl}$ and $20 \mathrm{mM}$ Tris- $\mathrm{HCl}(\mathrm{pH} 7.4)$ for measurement of lipid peroxidation. Renal protein was measured by the method of Lowry et al. (5) using bovine serum albumin as the standard. On day 3 after cisplatin treatment, urine was collected over a threehour period for the determination of platinum (Pt) content by atomic absorption spectrophotometry using a Shimadzu AA-670 spectrophotometer. Thereafter, plasma and renal tissue samples were collected from the anesthetized animals. Pt content in the plasma and kidney. which was digested in $61 \%$ $\mathrm{HNO}_{3}$ at room temperature overnight, was also analyzed.

Measurement of lipid peroxidation in kidney: Lipid peroxidation in homogenates of renal tissues was monitored by measuring the production of malondialdehyde using the thiobarbituric acid assay. The determination procedure was essentially the same as the method of Buege and Aust (6).

Determination of $p$-aminohippurate (PAH) accumulation in renal cortical slices: The ability of slices to accumulate PAH was determined as a biochemical parameter that would change in nephrotoxicity. At $72 \mathrm{hr}$ after cisplatin treatment, renal cortical slices were prepared free-hand with a razorblade on an ice-cold Petri-dish. The slices, weighing about $150 \mathrm{mg}$, were incubated at $37^{\circ} \mathrm{C}$ for $30 \mathrm{~min}$ in $10 \mathrm{ml}$ of incubation medium containing $134 \mathrm{mM} \mathrm{NaCl}, 5.9 \mathrm{mM} \mathrm{KCl}, 1.5 \mathrm{mM}$ $\mathrm{CaCl}_{2}, 1.2 \mathrm{mM} \mathrm{MgCl}, 11.5 \mathrm{mM}$ glucose, $5.8 \mathrm{mM} \quad \mathrm{N}$-2-hydroxyethylpiperazine- $N^{\prime}-2$ ethanesulfonic acid buffer ( $\mathrm{pH} 7.4$ ), 0.074 $\mathrm{mMPAH}$ and $1 \%$ inulin which was added to estimate the extracellular space of the slices. After incubation, the PAH and inulin levels in the slices and medium were analyzed by the methods of Bratton and Marshall (7) and Roe et al. (8), respectively. PAH accumulation was calculated as the ratio of concentration of $\mathrm{PAH}$ in the intracellular fluid (S) to that in the medium $(M)$, the $S / M$ ratio. The experimental methods of the slice-study were essentially the same as those already described (9).

Electron microscopy: Renal cortical tissue was fixed immediately in $2.5 \%$ glutaraldehyde in phosphate buffer, then postfixed with osmium tetroxide. The tissue was serially dehydrated in ethanol, infiltrated with propylene oxide, and mounted in Epon. Thin sections were stained with uranylacetate and lead nitrate, and analyzed in a Hitachi H-600 transmission electron microscope.

Chemicals and statistics: Cisplatin and $\alpha$ tocopherol were purchased from the Sigma Chemical Co. (St. Louis, MO). DPPD was obtained from Tokyo Kasei Kogyo Co., Ltd. (Tokyo, Japan). Other chemicals were of the highest purity available from commercial sources.

Data are expressed as means \pm S.E. Statistical analysis was done by analysis of variance. Significant differences at the level of $P<0.05$ were determined among multiple comparisons with Dunnett's test (10).

\section{Results}

Kidneys of rats injected with cisplatin ( 5 $\mathrm{mg} / \mathrm{kg}$ ) had a time-dependent increase in lipid peroxidation (Fig. 1). Up to $48 \mathrm{hr}$ after the injection of cisplatin, the malondialdehyde level did not increase, but it was progressively increasing at $72 \mathrm{hr}$. Since vitamin $E$ is an antioxidant and radical scavenger (11-13), our experiment was to determine if $\alpha$ tocopherol. one of the four tocopherols which constitute vitamin $E$, could prevent cisplatin induced lipid peroxidation. Treatment 
of rats with $\alpha$-tocopherol before the cisplatin injection delayed the increase in lipid peroxidation until almost $120 \mathrm{hr}$ after the injection (Fig. 1).

The $\alpha$-tocopherol did not completely prevent lipid peroxidation, but merely delayed it, so we tried the effect of DPPD, a more powerful free-radical scavenger $(14,15)$. Rats given DPPD before the injection of cisplatin $(5 \mathrm{mg} / \mathrm{kg}$ ) produced no significant change in the level of malondialdehyde in the kidney compared to the level at time zero (Fig. 1). Neither $\alpha$-tocopherol or DPPD alone affected the malondialdehyde level in the kidney (data not shown).

Our previous study showed that administration of cisplatin developed marked nephrotoxicity on day 3 , with an increase in plasma urea nitrogen, and the nephrotoxicity was attenuated by DPPD pretreatment (2). Renal high $\mathrm{Pt}$ content, which was accumulated $6 \mathrm{hr}$ after i.p. injection of cisplatin, decreased thereafter at a relatively rapid rate, but the rate of decrease in the $\mathrm{Pt}$ content in the kidney was relatively slow from $48 \mathrm{hr}$ over several days in rats and mice (16-18). Then, we examined whether the antioxidant, given $24 \mathrm{hr}$ before the injection of cisplatin, could have the effect on Pt distribution 3 days after cisplatin injection. The $\mathrm{Pt}$ content in renal cortical tissue and plasma and urinary $\mathrm{Pt}$

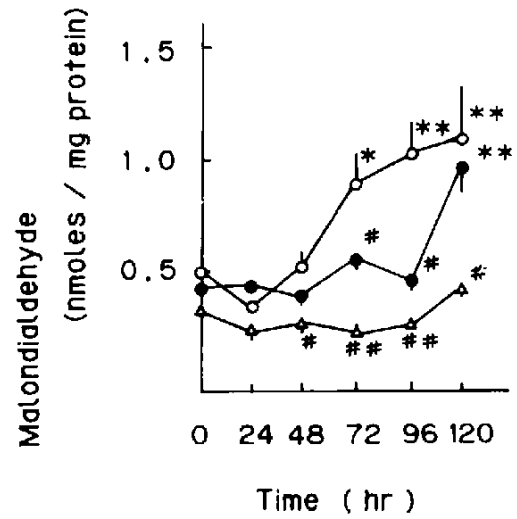

Fig. 1. Changes in renal malondialdehyde level caused by cisplatin in rats treated with $\alpha$-tocopherol (O). $N$ - $N^{\prime}$-diphenyl-p-phenylenediamine (DPPD, $\triangle$ ) or not (O). $\alpha$-Tocopherol $(1667 \mathrm{lU} / \mathrm{kg})$ or DPPD $(0.5 \mathrm{~g} / \mathrm{kg})$ was given i.p. $24 \mathrm{hr}$ before the injection of cisplatin ( $5 \mathrm{mg} / \mathrm{kg}$. i.p.). Data are the means $\pm S . E$. of six experiments. ${ }^{*} P<0.05$ vs. the control value at time zero. ${ }^{*} P<0.01$ vs, the control value at time zero. $P<0.05$ vs. the intoxicated group (cisplatin alone, 0 ) at the respective time. $P<0.01$ vs. the intoxicated group (cisplatin alone. $O$ ).

Table 1. Effect of $N$ - $N^{\prime}$-diphenyl-o-phenylenediamine (DPPD) on platinum (Pt) distribution

\begin{tabular}{|c|c|c|c|}
\hline -. - & $\begin{array}{l}\text { Urinary Pt excretion } \\
\text { Day } 3 \\
(\mu \mathrm{g} / 100 \mathrm{~g} / 3 \mathrm{hr})\end{array}$ & $\begin{array}{l}\text { Kidney cortical Pt } \\
\text { Day } 3 \\
(\mu g / g \text { kidney) }\end{array}$ & $\begin{array}{l}\text { Plasma Pt } \\
\text { Day } 3 \\
(\mu \mathrm{g} / \mathrm{ml})\end{array}$ \\
\hline Cisplatin & $0.285 \pm 0.11$ & $5.35 \pm 0.33$ & $0.09 \pm 0.02$ \\
\hline DPPD + Cisplatin & $0.286=0.06$ & $4.26 \pm 0.59$ & $0.08 \pm 0.03$ \\
\hline
\end{tabular}

$N$ - $N^{*}$-Diphenyl-p-phenylenediamine $(0.5 \mathrm{~g} / \mathrm{kg})$ was given i.p. $24 \mathrm{hr}$ before the injection of cisplatin $(7.5 \mathrm{mg} / \mathrm{kg})$. Data are expressed as the mean $\pm \mathrm{S}$. E. of eight experiments. There was no significant effect of DPPD on platinum distribution.

Table 2. Effect of DPPD on cisplatin-induced decrease of PAH accumulation in incubated slices

\begin{tabular}{lc}
\hline Treatment & PAH accumulation (S/M) \\
None & $12.59 \pm 0.94$ \\
Cisplatin alone & $8.74 \pm 0.40^{*}$ \\
DPPD+Cisplatin after $24 \mathrm{hr}$ & $10.81 \pm 0.59^{\sharp}$ \\
DPPD alone & $12.92 \pm 0.65$ \\
\hline
\end{tabular}

$N$-N'-Diphenyl-p-phenylenediamine (DPPD. $0.5 \mathrm{~g} / \mathrm{kg}$ ) was given $24 \mathrm{hr}$ before the injection of cisplatin $(7.5 \mathrm{mg} / \mathrm{kg})$. Kidney cortical slices were prepared from rats treated $72 \mathrm{hr}$ after the injection of cisplatin and incubated at $37^{\circ} \mathrm{C}$ for $30 \mathrm{~min}$. Data are expressed as the mean $\pm S$. E. of four to six experiments. *P<0.01 vs. "None". "P<0.05 vs. "Cisplatin alone". 
excretion were not affected by DPPD pretreatment.
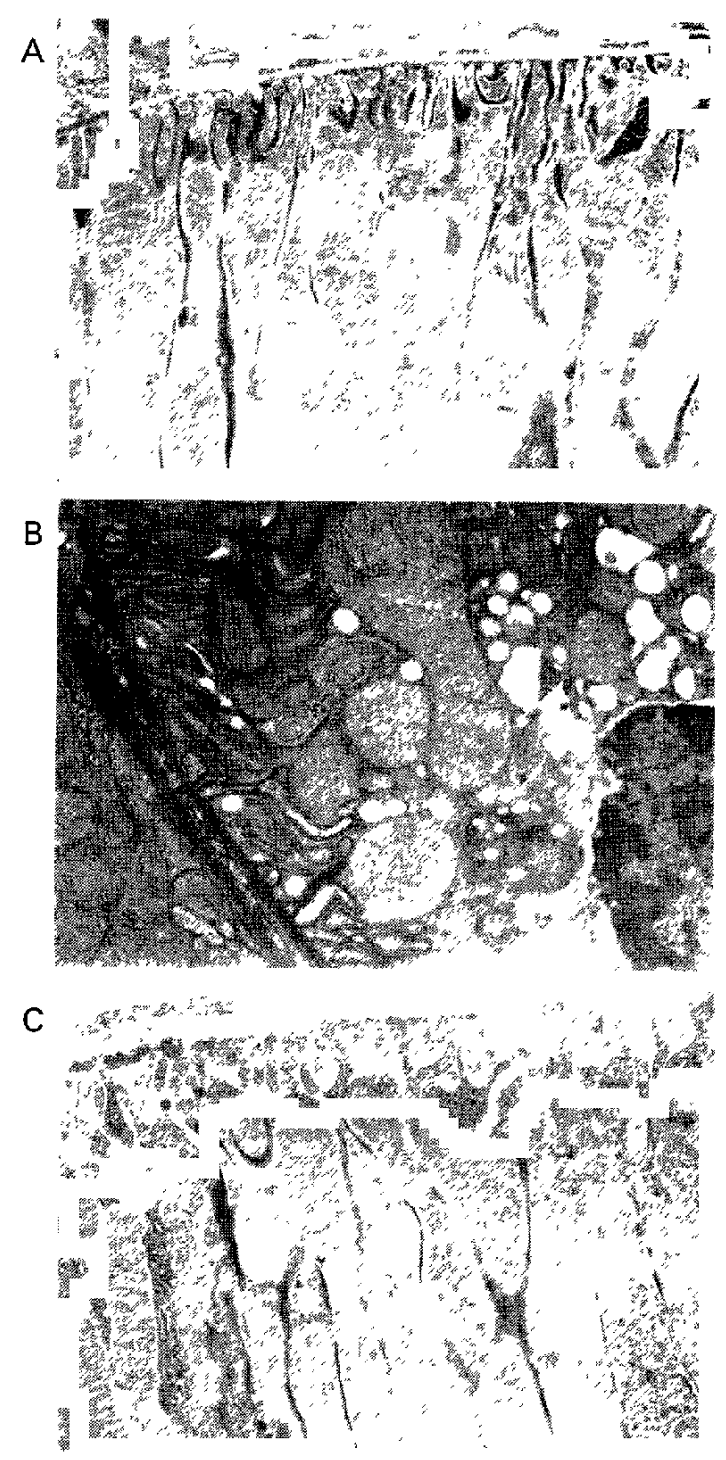

Fig. 2. Electron micrographs of renal proximal tubule from control rat (A), rat treated with cisplatın alone $(7.5 \mathrm{mg} / \mathrm{kg})(B)$, and rat pretreated with $N-N^{\prime}$ diphenyl-p-phenylenedıamıne $(05 \mathrm{~g} / \mathrm{kg}) 24 \mathrm{hr}$ before the administration of cisplatın (75 $\mathrm{mg} / \mathrm{kg}$ ) (C). Tissues were obtaıned $72 \mathrm{hr}$ after cisplatın or vehicle administration Tubular cells in photo $B$ showed numerous cytoplasmic vacuoles, rounded mitochondria with disordered cristae, disarrangement of basal infoldings, and dissociation of mitochondria from basal infoldings. There is little evidence of damaged cellular structure in photo $C . \times 20,000$
Table 2 shows that injection of cisplatin (7.5 $\mathrm{mg} / \mathrm{kg}$ ) significantly decreased the capacity of the incubated slices to accumulate PAH. Pretreatment with DPPD prevented the decrease. DPPD alone had no effect on the capacity to accumulate PAH by the slices.

Transmission electron microscopy was used to examine the effect of DPPD pretreatment on structural changes induced by the administration of cisplatın. After 3 days of cisplatın treatment $(7.5 \mathrm{mg} / \mathrm{kg})$, proxımal tubular cells of kidney showed numerous cytoplasmic vacuoles, rounded mitochondria with disordered cristae, disarrangement of basal infoldings and dissociation of mitochondria from basal infoldıngs (Fig 2B) as compared to the electron micrograph of proximal tubular cells from a control rat (Fig. 2A). These observations induced by the drug were almost consistent with those reported by Dobyan et al. (19). These structural changes caused by cisplatın were prevented by the pretreatment with DPPD ( $\mathrm{Fig} \mathrm{2C}$ ). DPPD alone had no effect on the structure of the cells (data not shown).

\section{Discussion}

The nephrotoxicity of cisplatin is allev.ated by Orgotern, which contains superoxide dismutase. (1) and by antioxidants such as $\alpha$-tocopherol and DPPD (2), whıch suggests that pathologic levels of oxygen radicals initiate lipid peroxidation Because of its simplicity. lipid peroxıdatıon was monitored using the level of malondialdehyde Results of this study showed that the renal level of malondialdehyde had started to increase $72 \mathrm{hr}$ after cisplatin was injected into the rats. This indicates that renal lipid peroxide and blood urea nitrogen (2) Increased at the same time. $72 \mathrm{hr}$ after cisplatın admınıstratıon. We investigated whether the renal malondialdehyde level could be reduced by antioxidants and found that $\alpha$-tocopherol given beforehand delayed the onset of the increase in renal IIpId peroxides caused by cisplatın. DPPD, a powerful free radical scavenger, completely prevented the increase in the lipid peroxidation caused by the drug without affecting $P_{i}$ distribution, I e.. Pt content in the plasma, kıdney cortex and urıne 3 days after cisplatin injection These results provide 
indirect evidence that cisplatin generates free radicals that interact with membrane lipids and consequently cause production of lipid peroxides. There is no direct evidence that lipid peroxidation plays a causative role in the development of cisplatin-induced nephrotoxicity. However, if the increase in lipid peroxidation were a result of cisplatin-induced nephrotoxicity rather than a cause of the nephrotoxicity, antioxidants such as $\alpha$ tocopherol and DPPD would not inhibit both increases in lipid peroxidation and urea nitrogen, but only the former. In fact, antioxidants inhibited both.

Biochemical evidence was presented in the present study to demonstrate that administration of DPPD actually modified a parameter that changes in nephrotoxicity, that is, DPPD pretreatment prevented the decrease in $\mathrm{PAH}$ accumulation in renal cortical slices from rats treated with cisplatin. Goldstein et al. (20) described that $\mathrm{PAH}$ accumulation in renal cortical slices from $\mathrm{F}-344$ rats given cisplatin i.v. in the dose of $5 \mathrm{mg} / \mathrm{kg}$ did not significantly decrease in comparison with that in the slices from control rats. We do not know whether the difference in our results came from the difference in the strain of rats used or from the different dose. The in vitro technique utilizing renal cortical siices for measurement of PAH accumulation is one of the methods used to study the secretory mechanism for PAH as the prototype for organic acids. Therefore, it appears that the decrease in the capacity to accumulate PAH by the slices from rats treated with cisplatin in the present study probably reflects the decrease in renal clearance and excretion of PAH induced by administration of cisplatin to experimental animals as reported already (20-22). In addition, histological evidence was also presented to demonstrate that DPPD pretreatment actually prevented the ultrastructural changes in renal proximal tubular cells of rats treated with cisplatin.

Fujita (23) demonstrated that cisplatin was found to elevate urinary activities of enzymes, $N$-acetyl-beta-glucosaminidase which is rich in lysosomes and alanine aminopeptidase in brush border membranes of renal cells, in patients. The possibility that membrane lipid peroxidation has a role as a primary event in the toxicity of chemicals has been suggested in recent years. The peroxidation of membrane lipids in lysosomes and brush borders probably results in enzyme leakage in tubules. Urinary enzyme activity was not monitored in the present study. Biochemical and histological evidence in the present study showed that DPPD prevented renal proximal tubular damage induced by cisplatin. So, we think that the antioxidant DPPD may have a preventive effect on the alterations in urinary enzyme activity by coping with the druginduced membrane lipid peroxidation.

Kuo et al. suggested that lipid peroxidation in cephaloridine-induced nephrotoxicity is initiated by superoxide radicals produced through redox cycling of the antibiotic in renal microsomes $(24,25)$. Increased formation of lipid peroxides in kidneys of rats poisoned with mercuric chloride may be due at least in part to decreased activity of glutathione peroxidase (26). It is still unknown whether the mechanism involved in cisplatin nephrotoxicity is in accord with either of the above concepts or not. Glutathione protects proteins and cell membranes against free radicals and peroxides; hydrogen peroxides and organic peroxides are metabolized by glutathione peroxidase. Studies on the effect of cisplatin on glutathione metabolism are in progress in our laboratory.

The present study shows that the antioxidants. which attenuated cisplatin nephrotoxicity (2), protected against the increase in lipid peroxidation and the biochemical and histological changes induced by cisplatin. We suggest that the nephrotoxic effect of cisplatin is associated at least in part with lipid peroxidation mediated by free radicals.

Acknowledgements: The authors are grateful to Ms. Caroline Latta and Mr. Tsutomu Iwamoto for help in preparing the manuscript and electron micrographs of tissue preparations, respectively.

\section{References}

1 McGinness, J.E., Proctor, P.H., Demopoulos, H.B., Hokanson, A. and Kirkpatrick, D.S. Amelioration of cis-platinum nephrotoxicity by Orgotein (superoxide dismutase). Physiol. Chem. Phys. 10, 267-277 (1978)

2 Sugihara, K. and Gemba, M.; Modification of 
cisplatin toxicity by antioxidants. Japan. $J$. Pharmacol. 40, 353-355 (1986)

3 Fridovich, 1.: The biology of oxygen radicals. Science 201, 875-880 (1978)

4 Slater, T.F.: Free-radical mechanisms in tissue injury. Biochem. J. 222, 1-15 (1984)

5 Lowry, O.H., Rosebrough, N.J., Farr, A.L. and Randall, R.J.: Protein measurement with the Folin phenol reagent. J. Biol. Chem. 193, 265275 (1951)

6 Buege, J.A. and Aust, S.D.: Microsomal lipid peroxidation. Methods Enzymol. 52, 302-310 (1978)

7 Bratton, A.C. and Marshall, E.K., Jr.: A new coupling component for sulfanilamide determination. J. Biol. Chem. 128, 537-550 (1939)

8 Roe, J.H., Epstein, J.H. and Goldstein, N.P.: A photometric method for the determination of inulin in plasma and urine. J. Biol. Chem. 178, 839-845 (1949)

9 Gemba, M., Tachibana, A., Sugihara, K., Hori, $M$. and Nakajima, M.: Inhibitory effect of lithium on $p$-aminohippurate transport in rat kidney cortex in vitro. Renal Physiol. 8, 179188 (1985)

10 Dunnett, C.W.: A multiple comparison procedure for comparing several treatments with a control. J. Am. Stat. Assoc. 50, 1096-1121 (1955)

11 Wasserman, R.H. and Taylor, A.N.: Metabolic role of fat-soluble vitamin D, E and K. Annu. Rev. Biochem. 41, 179-202 (1972)

12 Green, J.: Vitamin E and the biological antioxidant theory. Ann. N.Y. Acad. Sci. 203, 29-44 (1972)

13 Urano, S. and Matsuo, M.: A radical scavenging reaction of $\alpha$-tocopherol with methyl radical. Lipids 11, 380-383 (1976)

14 Masuda, Y. and Murano, T: Carbon tetrachlorideinduced lipid peroxidation of rat liver microsomes in vitro. Biochem. Pharmacol. 26, 2275-2282 (1977)

15 Cojocel, C., Laeschke, K.H., Inselmann, G. and Baumann, K.: Inhibition of cephaloridineinduced lipid peroxidation. Toxicology 35, 295305 (1985)

16 Choie, D.D., Del Campo, A.A. and Guarino, A.M.: Subcellular localization of cis-dichloro- diammineplatinum (II) in rat kidney and liver. Toxicol. Appl. Pharmacol. 55, 245-252 (1980)

17 Litterst, C.L.: Alterations in the toxicity of cisdichlorodiammineplatinum-II and in itssue localization of platinum as a function of $\mathrm{NaCl}$ concentration in the vehicle of administration. Toxicol. Appl. Pharmacol. 61, 99-108 (1981)

18 Osman, N.M., Copley, M.P. and Litterst, C.L.: Effects of the diuretics mannitol or acetazolamide on nephrotoxicity and physiological disposition of cisplatin in rats. Cancer Chemother. Pharmacol. 13, 58-62 (1984)

19 Dobyan, D.C., Levi, J., Jacobs, C., Kosek, J. and Weiner, M.W.: Mechanism of cis-platinum nephrotoxicity: II. Morphologic observations. J. Pharmacol. Exp. Ther. 213, 551-556 (1980)

20 Goldstein, R.S., Noordewier, B., Bond, J.T., Hook, J.B. and Mayor, G.H.: cis-Dichlorodiammineplatinum nephrotoxicity: Time course and dose response of renal functional impairment. Toxicol. Appl. Pharmacol. 60, 163-175 (1981)

21 Pera, M.F., Jr., Zook, B.C. and Harder, H.C.: Effects of mannitol or furosemide diuresis on the nephrotoxicity and physiological disposition of cis-dichlorodiammineplatinum-II in rats. Cancer Res. 39, 1269-1278 (1979)

22 Appenroth, D. and Bräunlich, $\mathrm{H}$.: Age differences in cisplatin nephrotoxicity. Toxicology $32,343-$ 353 (1984)

23 Fujita, K.: Comparison of the urinary enzyme reponses caused by nephrotoxic aminoglycoside and cis-platinum. Japan. J. Nephrol. 27, 1329$1332(1985)$

24 Kuo, C.-H., Maita, K., Sleight, S.D. and Hook, J.B.: Lipid peroxidation: A possible mechanism of cephaloridine-induced nephrotoxicity. Toxicol. Appl. Pharmacol. 67, 78-88 (1983)

25 Goldstein, R.S., Pasino, D.A., Hewitt, W.R. and Hook, J.B.: Biochemical mechanisms of cephaloridine nephrotoxicity: Time and concentration dependence of peroxidative injury. Toxicol. Appl. Pharmacol. 83, 261-270 (1986)

26 Yonaha, M., Itoh, $E_{.}$Ohbayashi, Y. and Uchiyama, M.: Induction of lipid peroxidation in rats by mercuric chloride. Res. Commun. Chem. Pathol. Pharmacol. 28, 105-112 (1980) 